\title{
Olfactory training changes electrophysiological responses at the level of the olfactory epithelium*
}

\author{
Thomas Hummel, Georg Stupka, Antje Haehner, Sophia C. Poletti \\ Smell and Taste Clinic, Department of Otorhinolaryngology, TU Dresden, Dresden, Germany
}

Rhinology 56: 4, 330-335, 2018

https://doi.org/10.4193/Rhin17.163

*Received for publication:

July 25, 2017

Accepted: January 22, 2018

Background: Olfactory training (OT) has been shown to increase olfactory performance in healthy subjects and patients with post-traumatic or post-infectious olfactory loss. Morphological correlates such as olfactory bulb volume increase and gray matter changes suggest central changes in olfactory brain areas following olfactory exposure. Some evidence from animal studies indicates peripheral changes upon OT whereas no such data exist in humans. This study explores the question whether changes in olfaction following OT are associated with alterations of the electro-olfactogram (EOG) derived from the olfactory epithelium.

Methodology: We compared electrophysiological EOG responses to a pleasant, rose-like odor (phenylethyl alcohol, PEA) and to an unpleasant odor (rotten eggs, $\mathrm{H}_{2} \mathrm{~S}$ ) in patients and controls. EOG were recorded in smell impaired patients before and after OT for a period of 4-6 months.

Results: EOG recordings following PEA and $\mathrm{H}_{2} \mathrm{~S}$ stimulation were significantly more often obtained in controls than in patients. OT was associated with a significantly higher number of EOG recordings.

Conclusions: OT is associated with an increase in EOG responses implicating stimulus-induced plasticity to start at the level of the olfactory epithelium.

Key words: olfaction, olfactory training, olfactory receptors, nose, electro-olfactogram

\section{Introduction}

Exposure to odors may improve olfactory function. Repeated exposure to odors in healthy subjects has been shown to increase olfactory sensitivity ${ }^{(1-3)}$; it also improves the recovery of patients with post-infectious olfactory loss ${ }^{(4,5)}$ and seems to prevent olfactory deterioration in older people ${ }^{(6)}$. Further on, patients with Parkinson's disease performing "olfactory training" (OT) were shown to improve in their olfactory ability ${ }^{(7)}$.

Few morphological correlates for OT effects have been described to date. At the level of the olfactory bulb OT has been shown to increase its volume in healthy volunteers ${ }^{(8)}$. In addition, changes in brain connectivity have been shown to be associated with $\mathrm{OT}^{(9)}$. At the level of the olfactory epithelium (OE) there is limited evidence that OT can induce changes; in rats electrophysiological responses from the OE were found to increase in response to odor exposure ${ }^{(10)}$.

Thus, assuming that olfactory input manipulation induces chan- ges at the $O E$ in humans, we set out to explore the influence of repeated exposure to odors on electro-olfactogram (EOG) recordings in patients with olfactory loss. EOG are generator potentials of olfactory receptor neurons in response to chemical stimuli; they pose a comprehensive way of assessing neural information from the periphery of the olfactory system ${ }^{(11-16)}$.

\section{Materials and methods}

The study was performed in accordance with the Declaration of Helsinki and was approved by the Ethics Committee of the TU Dresden (application number EK12012006).

\section{Participants}

Patients were randomly recruited from the Smell and Taste Clinic at the Department of Otorhinolaryngology. Informed consent was provided by each participant. The following inclusion and exclusion criteria were applied: 
The study included only participants aged 18 years and above. The patient group contained patients with post-infectious and idiopathic smell loss whereas participants from the control group had no impaired sense of smell as reflected in normosmic test results in the "Sniffin' Sticks" test (see below). Excluded from the study were patients or participants with acute or chronic sinunasal disease, chronic disease like Parkinson's disease or chronic renal failure associated with smell disorders, pregnant and lactating women.

With regard to those criteria a total number of 65 participants could be included in the study out of which 15 were anosmic (Ø age: 49, SD: 11.6), 23 hyposmic ( $~$ age: 55, SD: 11.2) and 27 normosmic (Ø age: 49, SD: 11.5). OT was performed only in smell impaired patients and included were only those with a complete pre and post training status (23 out of 38 ).

\section{Olfactory testing}

Olfactory testing was performed in 27 healthy participants and 38 patients ( 15 anosmics, 23 hyposmics) at baseline using the "Sniffin' Sticks" test. Out of 38 patients only 23 completed OT and underwent additional olfactory testing 4-6 months after OT. The "Sniffin' Sticks" test consisted of three subtests ${ }^{(17)}$. In the odor threshold task subjects had to detect the odorized (phenylethyl alcohol, PEA) pen among three samples with the other two pens containing the solvent, odorless propylene glycol. PEA concentration was increased if the subjects' answer was wrong and decreased if the given answer was correct. In the odor discrimination task again a triplet of pens was presented to the subject who had to discriminate one different odor from two identical odors. Regarding the odor identification task, subjects had to smell a single odorous pen and choose the correct answer from a list of four descriptors. The sum of the three tests accounted for the TDI- score with a maximum of 48 points (each subtest with 16 points). Normosmia was set at 30.5 points or more in the composite TDI score; hyposmia was diagnosed between 16.5 and 30.5 points and functional anosmia below 16.5 points ${ }^{(18)}$.

\section{OT}

Twenty-three patients completed OT for 4-6 months using four different odors (eucalyptol, citronellal, eugenol, phenyl ethyl alcohol). Odors were presented in brown glass jars containing a cotton pad soaked with $4 \mathrm{ml}$ of odor. Patients had to smell each odor twice in the morning and twice in the evening for 10 seconds.

\section{EOG recordings}

All subjects practised a specific breathing technique (velopharyngeal closure $\left.{ }^{(19)}\right)$ prior to the recordings. This technique avoids respiratory flow inside the nasal cavity during mouth breathing through lifting the soft palate and closing the nasopharynx. For chemical stimulation, an olfactometer was employed delivering the odorants to the left or right nostril without altering mechanical or thermal conditions at the stimulated mucosa ${ }^{(19,20)}$. Therefore, pulses of the stimulants were embedded in a constantly flowing air stream with controlled temperature $\left(36.5^{\circ} \mathrm{C}\right)$ and humidity ( $80 \% \mathrm{RH})$. The air stream was led into the nasal cavity with a flow rate of $6 \mathrm{~L} / \mathrm{min}$ by way of a Teflon ${ }^{\mathrm{TM}}$ tubing ( $8 \mathrm{~cm}$ length, $3 \mathrm{~mm}$ inner dia-meter). Two thirds of the maximum stimulus concentration were reached at the olfactometer's outlet within $20 \mathrm{~ms}^{(19)}$. For stimulation phenylethyl alcohol (40\% v/v PEA) and hydrogen sulfide (8 ppm $\mathrm{H}_{2} \mathrm{~S}$; air liquide, Düsseldorf, Germany) were chosen which are regarded to specifically activate the olfactory system ${ }^{(21-23)}$. In addition, $\mathrm{CO}_{2}(60 \% \mathrm{v} / \mathrm{v}$; air liquide, Düsseldorf, Germany) was used at concentrations which did produce clear trigeminally mediated sensations (e.g., burning or stinging).

White noise of approximately $50 \mathrm{~dB}$ SPL was used to mask switching clicks of the stimulator.

EOG was recorded by means of a tubular electrode filled with Ringer-agar (1\%) which contained a silver-chlorided silver wire (impedance $\leq 10 \mathrm{k} \Omega$ at $1 \mathrm{kHz}^{(11)}$, outer diameter $0.8 \mathrm{~mm}$ ). The electrode was placed under endoscopic control (Richard Wolf, Knittlingen, Germany; outer diameter $1.9 \mathrm{~mm}$ ) approximately $7 \mathrm{~cm}$ deep into the nasal cavity until the contact between electrode and mucosa had been established within the olfactory cleft. The recording site was marked on a sketch of the human nasal cavity ${ }^{(24)}$.

The electrode was then stabilized by means of adjustable clips on a frame similar to lensless glasses ${ }^{(12)}$. After a response had been established in return to stimulation with either $\mathrm{PEA}, \mathrm{H}_{2} \mathrm{~S}$ or $\mathrm{CO}_{2}$ the three stimuli were randomly applied 2-16 times at an interval of approximately $60 \mathrm{~s}$. Mucosal potentials were amplified, filtered (band pass 0.01-15 Hz; SIR, Röttenbach, Germany), and digitized (sampling frequency $125 \mathrm{~Hz}$, segments of $8192 \mathrm{~ms}$ ). After averaging, maximum EOG amplitudes (P1, N1, p1n1) and latencies $(\operatorname{lp} 1, \ln 1)$ were analysed for each individual. The clear delineation of a large negative response (N1 amplitude) was interpreted as a peripheral odor evoked potential or the existence of an EOG potential in response PEA or $\mathrm{H}_{2} \mathrm{~S}$.

\section{Statistical analysis}

Using SPSS 23.0 (SPSS Inc. Chicago, IL, USA) data were statistically analysed by means of t-tests for independent samples (because EOGs were obtained in inhomogeneous groups of people) to investigate differences between patients and controls for the different stimulus qualities. Using chi²-tests we also looked at differences between conditions in terms of the number of responses.

\section{Results}

Olfactory performance

There was no significant difference in age distribution between 

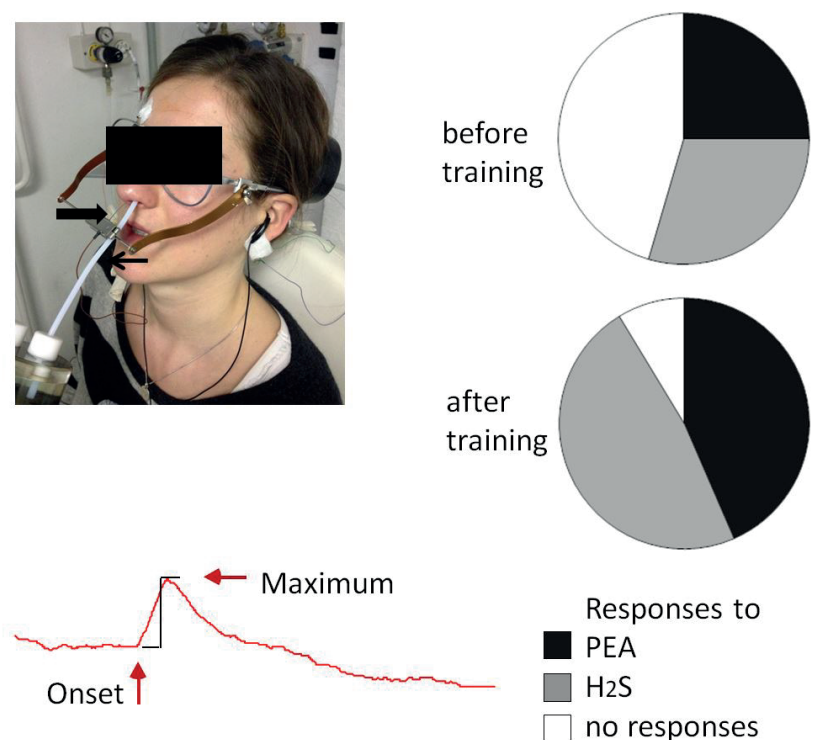

Figure 1. Top left: Participant with endonasal EOG electrode (thick black arrow) fixed to an adjustable clip on a lensless frame of glasses; stimuli are presented through thin cannula (thin black arrow). Bottom left: EOG recording from the $\mathrm{OE}$; top right: EOG responses to olfactory stimuli before training separately for stimulation with phenylethyl alcohol or hydrogen sulfide (total: $\mathrm{n}=46$ recordings); bottom right: $E O G$ responses after training (total: $\mathrm{n}=46$ recordings).

healthy, hyposmic and anosmic participants $(p=0.10)$ using analysis of variance. Comparing the three groups regarding their olfactory performance, a highly significant difference in TDI score and all subtests appeared (ps $<0.001$ ) at baseline. While healthy participants showed an average TDI score of 34.7 points ( $S D \pm 2.8$ ), hyposmic patients had a score of $23.6(S D \pm 4.0)$ und anosmic patients of 11.5 points ( $S D \pm 3.3$ ).

Patients $(n=23)$ performing OT showed an average TDI score of 19 points (SD \pm 7.9 ) at baseline. A significant improvement in olfactory performance could be shown in the identification task ( $t[22]=-3.59, p=0.002$ ). But no such difference could be demonstrated for the composite TDI, discrimination or threshold score $(p>0.05)$. A clinically relevant improvement of olfaction, which was defined as an improvement of 6 points within the TDI score $^{(25)}$, was seen in 8 (35\%) patients.

\section{EOG recordings}

Comparing healthy subjects' and patients' recordings at baseline EOG recordings were performed in 27 healthy subjects ( 20 women, 7 men, mean age 49 years; SD: 11.5) and 38 patients with olfactory loss (15 anosmic [ 6 women, 9 men $\varnothing$ age: 49, SD: 11.6], 23 hyposmic [17 women, 6 men, $\varnothing$ age: 55, SD: 11.2]). EOGs could be recorded in all subjects, however, not all subjects exhibited responses to all stimulus qualities (Table 1).

No significant differences in EOG amplitudes (P1, N1, P2, p1n1, $\mathrm{n} 1 \mathrm{p} 2)$ or latencies (Ip1, In1, Ip2, p2p1) emerged between the two groups (ps > 0.05). However, using the Chi-Square test, we
Table 1. EOG recordings in normosmic, hyposmic and anosmic participants.

\begin{tabular}{|lcccc}
$\begin{array}{l}\text { No. (\%) of } \\
\text { responses }\end{array}$ & $\begin{array}{c}\text { Normosmia } \\
\mathbf{n = 2 7}\end{array}$ & $\begin{array}{c}\text { Hyposmia } \\
\mathbf{n = 2 3}\end{array}$ & $\begin{array}{c}\text { Anosmia } \\
\mathbf{n}=\mathbf{1 5}\end{array}$ & p value \\
\hline $\mathrm{CO}_{2}$ & $27(100 \%)$ & $23(100 \%)$ & $15(100 \%)$ & n.s. \\
$\mathrm{PEA}$ & $26(96 \%)$ & $13(57 \%)$ & $8(53 \%)$ & $\mathrm{p}<0.001$ \\
$\mathrm{H} \mathrm{S}$ & $25(93 \%)$ & $14(61 \%)$ & $10(67 \%)$ & $\mathrm{p}=0.023$
\end{tabular}

Number (percentage, \%) of obtained EOG recordings to different stimulus qualities in normosmic, hyposmic and anosmic participants. Stimulus qualities: Carbon dioxide $\left(\mathrm{CO}_{2}\right)$, Phenylethyl alcohol (PEA), Hydrogen sulfide $\left(\mathrm{H}_{2} \mathrm{~S}\right)$; the $\mathrm{p}$-value shows the results of comparisons of the 3 groups using $\mathrm{Chi}^{2}$-tests.

could demonstrate that the N1 amplitude and therefore the response to PEA and $\mathrm{H}_{2} \mathrm{~S}$ was significantly more often present in healthy participants than in patients (Mann-Whitney U-test: PEA: $\left.Z=3.48, p<0.001, H_{2} S: Z=2.57, p=0.01\right)$. No such differences emerged in response to $\mathrm{CO}_{2}$ stimulation $(\mathrm{Z}=0.0, \mathrm{p}=1.0)$. In addition, significant differences occurred when comparing the number of responses between 3 groups of patients with normosmics having the largest number of responses. The number of patients showing EOG recordings to different stimuli separately for patients with anosmia, hyposmia and normosmia is shown in Table 1.

\section{Comparing patients' recordings before and after OT} Because 15 smell impaired patients were excluded from the study due to non-compliance or no-show, EOG recordings were compared in 23 (12 women, 11 men; $\varnothing$ age: 54 years, SD: 12.6) out of 38 patients before and after OT (Table 2). No significant differences in EOG amplitudes (P1, N1, p1n1) or latencies (Ip1, $\ln 1$ ) emerged between the groups ( $p>0.05)$. However, in terms of the number of responses to PEA and $\mathrm{H}_{2} \mathrm{~S}$, the following differences could be shown: in response to PEA and $\mathrm{H}_{2} \mathrm{~S}$, both specific activators of the olfactory system, a significantly higher number of EOGs could be recorded after OT (number of EOGs before OT: PEA $n=11, \mathrm{H}_{2} \mathrm{~S} n=13$; after OT: $P E A \mathrm{n}=20, \mathrm{H}_{2} \mathrm{~S}$ $\mathrm{n}=22$; Mann-Whitney U-test: PEA Z $=2.11, \mathrm{p}=0.035 ; \mathrm{H}_{2} \mathrm{~S} Z=2.53$, $p=0.011$ ). As mentioned above, clinically relevant improvement with a TDI score increase of 6 points was found in 8 out of 23 patients (35\%). Comparing improved patients $(n=7)$ with those showing no relevant improvement in TDI score $(n=16)$ no significant differences appeared in terms of the number of EOG recordings following PEA, $\mathrm{H}_{2} \mathrm{~S}$ and $\mathrm{CO}_{2}$ stimulation ( $\mathrm{p}>0.11$, Table 3).

\section{Discussion}

Major results in our study include 1) that EOG recordings fol- 
Table 2. EOG recordings in patients performing olfactory training.

\begin{tabular}{|lccc|}
$\begin{array}{l}\text { No. (\%) of } \\
\text { responses }\end{array}$ & $\begin{array}{c}\text { Before } \\
\mathbf{n = 2 3}\end{array}$ & $\begin{array}{c}\text { After } \\
\mathbf{n = 2 3}\end{array}$ & p value \\
\hline $\mathrm{CO}_{2}$ & $23(100 \%)$ & $23(100 \%)$ & n.s. \\
\hline $\mathrm{PEA}$ & $11(48 \%)$ & $20(87 \%)$ & 0.035 \\
\hline $\mathrm{H}_{2} \mathrm{~S}$ & $13(57 \%)$ & $22(96 \%)$ & 0.011 \\
\hline
\end{tabular}

Number (percentage, \%) of obtained EOG recordings to different stimulus qualities in patients before and after olfactory training. Stimulus qualities: Carbon dioxide $\left(\mathrm{CO}_{2}\right)$, Phenylethyl alcohol (PEA), Hydrogen sulfide $\left(\mathrm{H}_{2} \mathrm{~S}\right)$; the $\mathrm{p}$-value shows results of comparison (Wilcoxon-test) of the number of responses obtrained before and after olfactory training.

Table 3. EOG recordings in patients showing/ not showing significant clinical improvement after olfactory training.

\begin{tabular}{lccc}
$\begin{array}{c}\text { No. (\%) of } \\
\text { responses }\end{array}$ & $\begin{array}{c}\text { Olfactory } \\
\text { improvement } \\
<\mathbf{6} \text { points } \\
\mathbf{n}=16\end{array}$ & $\begin{array}{c}\text { Olfactory } \\
\text { improvement } \\
\mathbf{6} \text { } \text { points } \\
\mathbf{n}=\mathbf{7}\end{array}$ & p value \\
\hline $\mathrm{CO}_{2}$ & $16(100 \%)$ & $7(100 \%)$ & 1.0 \\
\hline $\mathrm{PEA}$ & $14(88 \%)$ & $6(86 \%)$ & 0.91 \\
\hline $\mathrm{H}_{2} \mathrm{~S}$ & $16(100 \%)$ & $6(86 \%)$ & 0.12 \\
\hline
\end{tabular}

Number (percentage, \%) of obtained EOG recordings to different stimulus qualities in patients showing an olfactory improvement of 6 and more points in TDI score and patients showing less than 6 points of improvement after olfactory training; the $\mathrm{p}$-value shows results of comparison (Chi ${ }^{2}$-test) of the number of responses obtained before and after olfactory training. Stimulus qualities: Carbon dioxide $\left(\mathrm{CO}_{2}\right)$, Phenylethyl alcohol (PEA), Hydrogen sulfide $\left(\mathrm{H}_{2} \mathrm{~S}\right)$.

lowing PEA and $\mathrm{H}_{2} \mathrm{~S}$ stimulation were significantly more often obtained in healthy participants than in anosmic and hyposmic patients. 2) OT was associated with a significantly higher number of EOG recordings in response to $\mathrm{H}_{2} \mathrm{~S}$ and PEA stimulation obtained from the olfactory mucosa. 3) No differences in electrical activation appeared in response to $\mathrm{CO}_{2}$ between healthy subjects and patients as well as 4) no differences emerged after OT as compared to baseline in response to trigeminal stimuli. Finally, 5) no significant differences in the number of EOG responses emerged between those patients experiencing a clinically relevant improvement after OT and those who did not.

At first, the current results suggest that olfactory impairment of various entities seems to start as early as at the level of the olfactory receptor neurons (ORN) which is reflected in a lower number of EOG recordings obtained from the olfactory mucosa of smell impaired patients. Both in post-traumatic ${ }^{(26)}$ and post-infectious olfactory ${ }^{(27)}$ dysfunction the $\mathrm{OE}$ is known to be markedly disorganized and the olfactory receptors diminished in number. Therefore, with the electrophysiological changes demonstrated in our study, those histopathological alterations seem not only to present morphological but also functional changes at the level of the ORN. A significantly lower olfactory performance in our patients as compared to healthy participants demonstrates the functional alteration on a psychophysical level which is further in line with the diminished electrophysiological response activity shown in our study. Hence, for the first time, a decreased peripheral electrical activity could be demonstrated in patients with acquired olfactory loss.

Second, our present data shows that OT is associated, at least to some extent, with an improvement of electrical activity at the $\mathrm{OE}$. This finding is in line with data from rats, where enhancement of the spatial activity pattern at the level of the olfactory mucosa was found following repeated exposure to odorants ${ }^{(10)}$. As suggested from previous work ${ }^{(28,29)}$ odor stimulation leads to cell depolarization of ORNs resulting in negative voltage transient which can be recorded from the mucosal surface. Hence, an improvement in EOG recording could indicate an increase in olfactory receptor expression or a higher affinity of those existing receptors caused by repeated short-term odor exposure. While the turnover of ORNs in rodents is known to take 30-90 days ${ }^{(30,31)}$ to our knowledge no clear data exist on the life span of human ORNs. However, considering the OT duration of 4-6 months, a quantitative increase in ORNs as a response to OT should additionally be taken into account. Because there was no control group to compare the results, we are finally not able to prove that the effects shown are caused by OT rather than spontaneous recovery. However, there is evidence in the literature for the superiority of OT over spontaneous recovery in improving olfactory performance ${ }^{(5,32)}$. Therefore, we assume that the increase in obtained EOG potentials after training was related to repeated short term odor exposure.

Additionally, a significant improvement in olfaction after OT could only be demonstrated for the identification task but not for the threshold or discrimination test which could also explain the overall limited improvement in electrical activity. Because we were able to record EOGs not only from hyposmic but also anosmic patients we could demonstrate the existence of remaining functional ORNs in anosmics which is in line with findings of Rawson et al. demonstrating functionally mature ORNs in Kallmann syndrome patients with bilateral anosmia(33). No difference in electrophysiological recordings between healthy and dysosmic patients or between pre- and posttraining status emerged in response to $\mathrm{CO}_{2}$ stimulation. Because $\mathrm{CO}_{2}$ represents a selective trigeminal stimulus, the obtained recordings present trigeminally mediated potentials rather than olfactory responses. Hence, as expected, OT did not show effects on trigeminal activation. There is evidence in the literature showing a reduced trigeminal sensitivity in patients with acquired 
olfactory loss ${ }^{(34)}$, which we could not find in the OE. This reduced trigeminal sensitivity is thought to be due to a lack of central nervous-interactions between the olfactory and trigeminal system whereas adaptive mechanisms seem to increase peripheral responsiveness ${ }^{(35)}$. Hence, according to our data, a reduced trigeminal sensitivity in acquired olfactory loss seems not to emanate from the periphery.

In those patients showing a clinically relevant improvement of 6 points in the TDI score ${ }^{(25)}$ after OT we could not obtain a higher number of EOG recordings as compared to those who did not improve. Probably a low number of subjects in both groups (7 vs. 16) could not represent the differences between the groups as seen in type two errors. On the other hand, we could show the existence of electrical potentials and therefore functioning ORNs in anosmic and non-improved patients as demonstrated in Kallmann syndrome patients by Rawson et al. ${ }^{(33)}$.

Although the current study involved patients with various causes of olfactory loss the aim of the study was not to study these different groups. As a consequence, the number of patients in the 21 groups of patients with idiopathic and postinfectious olfactory loss was too small (in total $n=23$ ) to allow for meaningful statistical comparisons between these groups in relation to the effects of OT. Future studies, however, will focus on the possible differences in EOG responses in patients with various causes of olfactory loss in relation to changes in olfactory function.

\section{Conclusion}

In conclusion, we could show for the first time that olfactory disorders were associated with a decreased number of peripheral electrical responses. OT on the other hand was, at least to some extent, associated with a stimulus-induced plasticity at the level of the ORNs. Therefore, OT in humans seems not only to affect olfactory processing at the central level as described so far but also at the level of the OE.

\section{Acknowledgements}

This work was supported by a grant from the 'Deutsche Forschungsgemeinschaft' to TH (DFG HU441/18-1). SCP was granted by the 'Dresden Fellowship Program' of the "Technische Universität" (TU) Dresden.

\section{Authorship contribution}

$\mathrm{TH}$ : Study conception and design, analysis and interpretation of the data, drafting and critical revision of the manuscript; GS: Study conception, data acquisition and critical revision of the manuscript; $\mathrm{AH}$ : Data acquisition and critical revision of the manuscript; SCP: Analysis and interpretation of the data, drafting and revising of the manuscript.

\section{Conflict of interest}

$\mathrm{TH}, \mathrm{GS}, \mathrm{AH}, \mathrm{SCP}$ declare that they have no conflict of interest.

\section{References}

1. Engen T, Bosack TN. Facilitation in olfactory detection. J Comp Physiol Psychol 1969; 68:320-6

2. Rabin MD. Experience facilitates olfactory quality discrimination. Percept Psychophys. 1988; 44:532-40.

3. Dalton P, Doolittle N, Breslin PA. Genderspecific induction of enhanced sensitivity to odors. Nat Neurosci 2002; 5:199-200.

4. Hummel T, Reden KRJ, Hähner A Weidenbecher M, Hüttenbrink KB. Effects of olfactory Training in patients with olfactory loss. Laryngoscope 2009; 119: 496-9.

5. Damm M, Pikart LK, Reimann H, Burkert S, Göktas Ö, Haxel B, et al. Olfactory training is helpful in postinfectious olfactory loss: a randomized, controlled, multicenter study. Laryngoscope 2014; 124: 826-31.

6. Schriever VA, Lehmann S, Prange J, Hummel T. Preventing olfactory deterioration: olfactory training may be of help in older people. J Am Geriatr Soc 2014; 62:384-6.

7. Haehner A, Tosch C, Wolz M, Klingelhoefer L, Fauser M, Storch A, et al. Olfactory Training in Patients with Parkinson's Disease. PLoS One 2013; 8:1-7.

8. Negoias S, Pietsch K, Hummel T. Changes in olfactory bulb volume following lateralized olfactory training. Brain Imaging Behav 2016; 22:1-8.

9. Kollndorfer K, Fischmeister FPS, Kowalczyk
K, Hoche E, Mueller CA, Trattnig S, et al. Olfactory training induces changes in regional functional connectivity in patients with long-term smell loss. Neurolmage Clin 2015; 9:401-10

10. Youngentob SL, Kent PF. Enhancement of odorant-induced mucosal activity patterns in rats trained on an odorant identification task. Brain Res 1995; 670:82-8.

11. Ottoson D. Analysis of the electrical activity of the olfactory epithelium. Acta Physiol Scand Suppl 1955; 35:1-83.

12. Knecht M, Hummel T. Recording of the human electro-olfactogram. Physiol Behav 2004; 83:13-9.

13. Hummel T, Knecht M, Kobal G. Peripherally obtained electrophysiological responses to olfactory stimulation in man: electro-olfactograms exhibit a smaller degree of desensitization compared with subjective intensity estimates. Brain Res 1996; 717:160-4.

14. Hummel T, Mojet J, Kobal G. Electroolfactograms are present when odorous stimuli have not been perceived. Neurosci Lett 2006; 397:224-8.

15. Lapid $H$, Shushan S, Plotkin A, Voet $H$ Roth Y, Hummel T, et al. Neural activity at the human olfactory epithelium reflects olfactory perception. Nat Neurosci 2011; 14:1455-61.

16. Lapid H, Seo H-S, Schuster B, Schneidman E, Roth $Y$, Harel D, et al. Odorant concentration dependence in electroolfactograms recorded from the human olfactory epithelium. J Neurophysiol 2009; 102:2121-30.

17. Hummel T, Sekinger B, Wolf SR, Pauli E, Kobal G. "Sniffin" sticks': olfactory performance assessed by the combined testing of odor identification, odor discrimination and olfactory threshold. Chem Senses 1997; 22:39-52.

18. Kobal G, Klimek L, Wolfensberger M, Gudziol $\mathrm{H}$, Temmel A, Owen CM, et al. Multicenter investigation of 1,036 subjects using a standardized method for the assessment of olfactory function combining tests of odor identification, odor discrimination, and olfactory thresholds. Eur Arch Otorhinolaryngol 2000; 257:205-11.

19. Kobal G. Elektrophysiologische Untersuchung des menschlichen Geruchssinns. In: Stuttgrat: Thieme Verlag. 1981.

20. Kobal G, Hummel C. Cerebral chemosensory evoked potentials elicited by chemical stimulation of the human olfactory and respiratory nasal mucosa. Electroencephalogr Clin Neurophysiol Evoked Potentials. 1988; 71:241-50.

21. Doty RL, Brugger WE, Jurs PC, Orndorff MA Snyder PJ, Lowry LD. Intranasal trigeminal stimulation from odorous volatiles: Psychometric responses from anosmic and normal humans. Physiol Behav 1978; 
20:175-85

22. Kobal G, Thiele V. Vergleich der objektiven und subjektiven Methoden olfaktometrischer Bestimmungen: Beispiel Schwefelwasserstoff. Schriftenr der Landesanstalt für Immissionsschutz des Landes NW. 1984; 59:41-47.

23. Hummel T, Pietsch H, Kobal G. Kallmann's syndrome and chemosensory evoked potentials. Eur Arch Otorhinolaryngol 1991; 248:311-2.

24. Lang J. Clinical anatomy of the nose, nasal cavity and paranasal sinuses. In: Stuttgart: Thieme Verlag. 1989

25. Gudziol V, Lötsch J, Hähner A, Zahnert T, Hummel T. Clinical significance of results from olfactory testing. Laryngoscope. 2006 116:1858-63.

26. Jafek BW, Eller PM, Esses BA, Moran DT. Posttraumatic anosmia. Ultrastructural correlates. Arch Neurol 1989; 46:300-4.

27. Moran DT, Jafek BW, Eller PM, Rowley JC Ultrastructural histopathology of human olfactory dysfunction. Microsc Res Tech 1992: 23:103-10

28. Simmons PA, Getchell T V. Neurogenesis in olfactory epithelium: loss and recovery of transepithelial voltage transients following olfactory nerve section. J Neurophysio 1981; 45:516-28.

29. Getchell T, Getchell M. Peripheral mechanisms of olfaction: biochemistry and neurophysiology. Neurobiolo. Finger TE and Silver WL, editor. Malabar: Krieger Publishing.: 1991. 91-123 p.

30. Yu CR, Wu Y. Regeneration and rewiring of rodent olfactory sensory neurons. Exp Neurol 2017; 287:395-408

31. Mackay-Sim A, Kittel PW. On the Life Span of Olfactory Receptor Neurons. Eur Neurosci 1991; 3:209-15.

32. Sorokowska A, Drechsler E, Karwowski M Hummel T. Effects of olfactory training: a meta-analysis. Rhinology 2017; 55:17-26.

33. Rawson NE, Brand JG, Cowart BJ, Lowry $L D$, Pribitkin E a, Rao VM, et al. Functionally mature olfactory neurons from 2 anosmic patients with kallmann-syndrome. Brain Res 1995:681:58-64.

34. Frasnelli J, Hummel T. Interactions between the chemical senses: trigeminal function in patients with olfactory loss. Int J
Psychophysiol 2007; 65:177-81.

35. Frasnelli J, Schuster B, Hummel T. Subjects with congenital anosmia have larger peripheral but similar central trigeminal responses. Cereb Cortex 2007; 17:370-7.

Thomas Hummel, MD

Smell \& Taste Clinic

Department of Otorhinolaryngology

TU Dresden

Fetscherstrasse 74

01307 Dresden

Germany

Tel: +49-351-458-4189

Fax +49-351-458-4326

E-mail:

thummel@mail.zih.tu-dresden.de 